READERS' ADVISORY

Laurel Tarulli, Editor
Bias in Readers' Advisory Services

\section{Laurel Tarulli}

Correspondence to this column should be addressed to Laurel Tarulli, Librarian and Information Services Manager, Sacred Heart School of Halifax, e-mail: laureltarulli@yahoo.com. ast week, while reading through the posts on one of our professional Listservs, a query came across asking for recommendations. This colleague indicated that she had been asked to make available weekly a collection of timely news articles to keep her community informed on politics and current events; however, as a selfproclaimed strong left-wing liberal, she has no knowledge of conservative resources. This gave me pause. As people, we have our viewpoints, opinions, and political leanings, but should our personal preferences have such a profound influence on our users that, up until now, this colleague didn't realize or concern herself with the fact that she had been providing reading suggestions that reflected her world view, and not necessarily that of the entire community? Indeed, as informational professionals, shouldn't we strive to know all of the available resources and viewpoints, even if we choose to seek only one perspective in our personal lives?

This is, perhaps, a harsh view, but it is easy for any of us to find ourselves in this situation. Are the conservative resources wrong or illegitimate because they do not fall in line with mainstream media sources? Should we not, as professionals, strive to remain hypervigilant of letting our own preferences influence the reading suggestions and resources we provide to our community? And should we not seek to find credible resources on both sides, rather than disregard that which we don't like or don't agree with, understanding that even resources or books we enjoy might contain bias or false information? Indeed, as people, we all strive to find voices familiar to ours or that resonate with us, whether or not they are always true or grounded in facts.

This awareness of striving to provide a balanced perspective has to be present in all areas of librarianship, from collection development and cataloging through references and readers' services. This is because there is no area of our profession that isn't touched by bias. Bias exists in our knowledge of genres, preferences when suggesting books, opinions on what readers are currently reading, and words we use (or don't use) during the readers' advisory interview. Even our book displays are presented in a way to influence our readers' choices or to persuade. Contrary to what many (nonlibrarians) believe is new in this Trump-era society, false information and bias is not new. Indeed, churches and art museums have been using techniques to influence, bias, and shape societal and political opinions for centuries. Magazines, newspapers, and works of fiction and nonfiction are all guilty of persuading, altering reality, influencing, and creating conspiracy theories. In her book, Civilizing Rituals, 
Carol Duncan examines how the use of words to describe a piece of art and, indeed, the physical structures themselves influence thought and behaviour. ${ }^{1}$ We have witnessed this influence in Carnegie libraries versus modern library designs. Carnegie libraries imposed a specific expectation of behavior, awe, and culture in which society reacted and conducted itself accordingly, while modern libraries strive to put our users at ease, providing feelings of comfort and accessibility, rather than elitism and deference. In Civilizing Rituals, Duncan also addresses the importance that words and their association with pieces of art have on influencing the thoughts and beliefs of viewers. ${ }^{2}$ The power to influence thought through a few words of description is startling, yet very real. We do not question the description placed next to a work of art; we accept it as truth. We accept it as truth because we trust that the information provided is not false. Why? Art galleries, like libraries, hold the public trust. We have a place in society that has resulted in an absolute faith in our mission to take into consideration the care of our users, and not to abuse nor mislead them. This is true in large public libraries, special libraries, and school libraries.

\section{BIAS IN SUBJECT HEADINGS}

Several years ago, I had a serious discussion with a colleague of mine regarding the power of subject headings in libraries. Subject terms, applied by catalogers, came into question regarding their role in readers' services. Do they intimidate, persuade, or dissuade a reader because of the terms chosen by a cataloger? Do they mislead? Or spoil a story? These are meaningful questions that resulted in a lively conversation. Catalogers, and more frequently publishers, label fiction for access, but the people ascribing these subject headings do not read every book, nor will they always like the title that they are cataloging. In fact, some professionals providing access to specific titles might find themselves tasked with assigning access points to publications that are in direct opposition to their belief system. Is there room here for error or, perhaps, misjudgment and, ultimately, erroneous or misleading subject headings?

Many a cataloging acquaintance has joked that access and the allure of certain books can be controlled by the access points and descriptive language used by catalogers. You don't want an anti-romance reader to label romance fiction as "smutty" for an access point, but a fan of romance also can't provide a list of subject headings that dilute the function of these headings. Neither one of these scenarios is helpful, but we have all observed headings that don't clearly represent the theme of the story. They often reflect a major event, conflict, location, or individual. Even with these formulaic elements, there is still room for error. This is especially true as more access points start to focus on the event, or conflict, rather than the "hard facts" of a book. Unlike nonfiction, fiction is often the unfortunate victim of subject headings that might be erroneously applied. Was the story really focussed on sisters and interpersonal relations? Was it school fiction, or did it just deal with kids that are school aged? Unfortunately for readers' services and readers' advisors, fiction titles make up the majority of publications of which our readers are seeking suggestions.

How many of us, in our quest to use the catalog to support reading suggestions, have found the subject headings not particularly useful or descriptive of the contents of the book? This is usually true for lesser-known titles that we might have knowledge of, but the individual adding the subject headings did not. While the intention to add appropriate subject headings to the bibliographic record is honorable and well meant, they might present an aspect of the story that is either incorrect, meaningless, or secondary. This is not to criticize the hard work that goes into subject headings, for which I am a strong supporter. Indeed, subject headings and genre headings are key access points and often assist users and our colleagues in making connections between titles, series, and a variety of other elements when choosing books. However, it is important to consider that these subject headings and even genres, by their very nature, are biased and often shape the readers' opinion of a book before the first page is read. Subject headings and genres, though, are not the only possible methods for misleading readers on their quest to find the next great read.

\section{READERS' SERVICES: CONVERSATIONS}

We often say, with a tongue-in-cheek tone, "a rose by any other name," and leave the sentence hanging. My children often play silly games, substituting one word of a song or book for another. This often changes the meaning completely, from something serious to silly, or from one topic to another. One word-how powerful.

Now we can take this same idea and apply it to the readers' services interview. Our choice of words used to suggest a book, similar to terms chosen by a cataloger, may very well influence our reader in a variety of ways. We might sell the book and entice them to choose it, turn them off, anger them, shut them down, pique their interest, and so on. The words we use reflect our education, social status, comfort level with the readers' services interview, comfort with the genre or reading preferences we're discussing, and our own cultural background and experiences. That's a lot of factors influencing our choice of adjectives, appeals, and descriptions when discussing books! It's also something that many experienced readers' advisors have become quite mindful of, as well as something that reinforces the value of the terms we use to describe books.

Readers' services and our conversations with readers require as much professionalism and ethical treatment as any information-seeking query. To readers, the query is very personal, and, because of this emotional connection, it is often 


\section{READERS' ADVISORY}

much easier to offend a reader with the response than, say, a research question at the information desk. Indeed, many local and state library associations provide outlines for the mission of readers' services and the nature in which they should be conducted. While they often feel less formal and more like a conversation, it's easy for a professional to forget that they must at all times maintain a professional separation and not become too familiar or at ease for a very human reason-allowing our personal opinions to color the words we use to suggest reading choices.

According to the Southern Ontario Library Service (SOLS), "just as in reference service, all staff must remember that readers' advisory work involves ethical decisions. Any requests which fit into a readers' advisory category should carry just as much weight as an informational or reference request." SOLS goes on to state, "People should never have to apologize for their reading interests. People read books for a variety of reasons-for information, understanding, education, entertainment, introspection, hope, confidence, connectivity, escape, challenge and even for reassurance."4 Indeed, the entire seventeen-page document outlines the importance and challenge of readers' services, emphasizing the more familiar conversation we are attempting to have with a reader, and yet striving to maintain a formula to help suggest a book. But what is interesting-or perhaps what we can highlight as absent from the document-is an area discussing the vocabulary and terms we use with our readers. In other words, guidance or a reminder as to how our body language and descriptive personality will influence the suggestions we make and our readers' experiences with us is needed.

What are some common areas that influence our reading suggestions to a reader? Think about the following and consider how they show, or are represented in, your body and language during the readers' services interview:

- Body language (leaning in, shoulder position, casually leaning to one side, crossed arms, hand on your hip, etc.). Ask yourself, What do these different body positions infer in a conversation?

- Inflection and tone. Are you speaking in a quiet tone? Confident? Abrasive or authoritative? Are your questions direct or abrupt? Dismissive or light and welcoming? Do you speak with an inflection that goes up at the end, as if asking questions?

- Vocabulary. What types of adjective do you use to describe books or, more importantly, genres? Some adjectives might reflect a lack of knowledge, but others reflect personal beliefs, education, or life experience.

Some might also consider facial expressions as a consideration when speaking with readers. What type of resting face do you have when listening to a reader describe a book? Is it open and welcoming? Serious? These are all good personal characteristics that are part of who we are but also might come across as negative, intimidating, or even a bit to "peppy" for a reader.

Many might indicate that if a reader returns for more suggestions, we are doing well; however, is that too simple a method to measure our success? SOLS is not the only library district that neglects to mention the importance of remaining aware of our own preferences and body language during the readers' advisory services interview. And, perhaps, this is a discussion to be had within our libraries. If we indicate that there is an element of ethical decision-making involved in readers' advisory services, do we need to outline how to strive for impartiality while cultivating an informal discussion and sense of ease with our readers? Does this, then, become too formulaic? Do we all just take it for granted that as professionals, we do not (or have never) used terms to describe a book based on personal preferences or bias, or with a view to influencing a reader? While this is often, or could often be, emphasized in readers' services training, it is also a vital element of this service that builds or erodes trust between a readers' advisor and reader. It is certainly something that is worthy of reflection and consideration for each of us.

\section{CONCLUSION}

One of the strengths of librarianship is our humanity, our personal relationships with users, and our attempt to find books and information that match a person to a meaningful literary experience-whatever that means to the individual. But with that personal touch comes bias in everything that we do. That is because, by its very nature, readers' services is selective in nature, rather than subjective. Our book displays, book conversations, readers' services terms, and efforts to label appeals, as well as our access points in our bibliographic records and classification schemes, all influence our readers. Even our most diligent efforts to promote displays with a caveat that they might offend or not appeal to a specific demographic will ultimately influence how readers view us and will impact them emotionally. As stated previously, even our buildings are meant to influence the feeling our readers have when they enter the library.

While it may appear that this article is primarily meant to undermine the strength of readers' services, it is, in fact, meant to call attention to an aspect of this service that falls into the general public's growing interest and concern over false and biased information. In this current environment, it is essential we examine all of our services, even our most successful, with a view to how our public might perceive our service and to the areas that might cause concern. Indeed, with society becoming more aware that they must question the value of the information they are fed, we might find ourselves defending our reading suggestions should we not take time to reflect on the language used within readers' services 
and strengthen our already strong and trusted service. If nothing else, there is always value in considering our own values and backgrounds and how that shapes what we do in our profession, and how successfully we are achieving our goals.

\section{References}

1. Carol Duncan, Civilizing Rituals: Inside Public Art Museums (New York: Routledge, 1995).
2. Ibid.

3. "Readers' Advisory Service," Southern Ontario Library Association, accessed November 12, 2017, http://www.sols.org/files /docs/develop/publications/sourcebook/sourcebookservices 2readersadv.pdf.

4. Ibid. 